\title{
Synthesis and assessment of novel self-doped poly (5-nitro-orthanilic acid) as a multifunctional scaling inhibitor on controlling the precipitation and crystal growth of $\mathrm{CaCO} 3$ and $\mathrm{CaSO} 4$ in solution
}

Hammed H. A. M. Hassan ( $\sim$ hamed.hassan@alexu.edu.eg )

Alexandria University

Dalia E. Abd-El-Khalek

National Institute of Oceanography and Fisheries

Marwa Abdel Fattah

Higher institute of engineering and technology

\section{Research Article}

Keywords:

Posted Date: February 9th, 2022

DOI: https://doi.org/10.21203/rs.3.rs-1281402/v1

License: (c) (i) This work is licensed under a Creative Commons Attribution 4.0 International License.

Read Full License 


\title{
Synthesis and assessment of novel self-doped poly (5-nitro-orthanilic acid) as a multifunctional scaling inhibitor on controlling the precipitation and crystal growth of $\mathrm{CaCO}_{3}$ and $\mathrm{CaSO}_{4}$ in solution
}

\author{
Hammed H. A. M. Hassan*, Dalia E. Abd-El-Khalek ${ }^{\text {b }}$ Marwa Abdel Fattah $^{\mathrm{c}}$
}

${ }^{\text {a }}$ Chemistry department, Faculty of Science, Alexandria University, P.O. 2, Moharram Beck, Alexandria, Egypt.

${ }^{\mathrm{b}}$ Marine Chemistry Department, National Institute of Oceanography and Fisheries, Alexandria, Egypt.

${ }^{\mathrm{c}}$ Chemical engineering department, Higher institute of engineering and technology, Menoufia, Egypt.

Correspondence to: Hammed H. A. M. Hassan (E-mail: hamed.hassan@alexu.edu.eg)

\begin{abstract}
:
Self-doped- and nitro-polyanilines have become a widely used strategy to optimize the electronic and vibratory spectra of polymeric building blocks in various applications. We report the synthesis of poly (5-nitro-orthanilic acid) by an aniline-initiated oxidative polymerization reaction. The polymer is characterized by spectroscopic techniques, elemental shapes, cyclic voltammetry, electrical conductivity, microscopic and thermal measurements. The hydrophilic and hydrophobic nature of the supports provided the formation of amphiphilicity as judged by SEM. Thermogravimetric measurements reveal thermal stability up to $500{ }^{\circ} \mathrm{C}$ and glass temperature $(\mathrm{Tg})$ observed at $240{ }^{\circ} \mathrm{C}$. Electrical conductivity decreases as the temperature rises at the different frequencies used, reflecting the semiconducting nature in the extrinsic range, which is characterized by high carriers and low mobility. The presence of these electron residues causes a decrease in efficiency and increases the thermal conductivity. Dielectric measurements have shown that permittivity decreases gradually at lower levels, mainly due to the transport of charging carriers, resulting in higher performance. The testing of the copolymer as a new scale blocker has resulted in moderate to fairly high performance. This effect is attributed to the change in polymer geometry using intramolecular $\mathrm{H}$-bonding group $-\mathrm{SO}_{3} \mathrm{H}$ and a chain polymer in an aqueous medium.
\end{abstract}

\section{Introduction}

Scale formation is commonly encountered and poses problems in water boilers coolers and oil well water, which cause a negative impact on operating systems and equipment, reducing heat transfer as an insulating layer and downhole completion equipment ${ }^{1}$. Among common encountered scaling cations in aqueous systems are $\mathrm{Ca}^{2+}$ cations, which deposit calcium carbonate and/or calcium sulfate. Sulfate scales are often attributed to the mixing of the incompatible sea- and formation waters, where the concentrations of calcium ions are high in both ${ }^{2}$. Carbonate scale, on the other hand, is generally attributed to the process of self-scaling, where the loss of carbon dioxide gas from the water to the hydrocarbon phase as pressure falls ${ }^{3}$. Main carbonates scale are Calcite $\mathrm{CaCO}_{3}$, Vaterite $\mathrm{CaCO}_{3}$, Aragonite $\mathrm{CaCO}_{3}$, Siderite $\mathrm{FeCO}_{3}$, and Dolomite $\mathrm{CaMg}\left(\mathrm{CO}_{3}\right)_{2}$. Functionalized organic polymers are green scale inhibitors and have shown excellent properties in delaying, reducing, and/or preventing scale deposition ${ }^{4}$. The effectiveness of these inhibitors depends on the chain length of the polymers and thus, the efficiency order in most cases was a low chain- $>$ higher chain lengths, where the polymeric repeating units were nearly $10-15^{5}$. 
The preparation of the self-doped polyaniline ${ }^{6}$ has become a widely used strategy and the results clearly indicated that introducing the $-\mathrm{SO}_{3} \mathrm{H}$ (electron-attracting) group on the polyaniline backbone makes them promising building blocks for different directions in the applications ${ }^{7}$. In the meantime, the introduction of $-\mathrm{NO}_{2}$ group substitution into polyaniline chains modifies the electronic and vibrational spectra of the resultant polymer ${ }^{8}$. Generally, aniline derivatives containing weak electron-withdrawing groups form a stable free radical during polymerization and the reaction occurs slowly due to some decrease in the electron density on the aniline' nitrogen atom ${ }^{9}$. However, anilines containing a strong electron-withdrawing substituent, such as $-\mathrm{NO}_{2}$, produced an unstable radical intermediate, and thus, polymerization does not occur, and to solve this obstacle, a trace amount of aniline as an initiator/promoter improved the reaction rate and yield ${ }^{10}$. The readily synthesized poly (nitroaniline-co-aniline) in various molar ratios have been used as an effective green step for the removal of toxic by-products obtained from various dyes and textile industries ${ }^{11}$. Nevertheless, investigations concerning introducing $-\mathrm{NO}_{2}$ substituent onto self-doped polyaniline and the expected variation of physicochemical properties in the resultant polymers remain unexplored. In this work, poly (4-nitroaniline-2-sulfonic acid) catalyzed by aniline (10 mole \%) was prepared by persulfate oxidative polymerization procedure and the resultant polymer was characterized by various techniques such as FTIR- and UV-visible spectroscopies, elemental analysis, scanning- and transmission electron microscopy (SEM, TEM), thermal analysis (TGA, DTG, DSC), electrochemical behavior and electrical and dielectric properties. Noteworthy, derivatives based (4-nitroaniline-2-sulfonic acid) were used, among many others, as sensing elements of optical sensors to determine sulfate in water and soil extracts ${ }^{12}$. As a continuation of our recent interests ${ }^{13}$, the assessment of the prepared poly (4-nitroaniline-2-sulfonic acid), for the first time, as a new scale inhibitor of $\mathrm{CaCO}_{3}$ and $\mathrm{CaSO}_{4}$ using slandered NACE, electrochemical tests and microscopic examinations was the main objective. The measurements were performed on as-synthesized samples, without the further re-doping procedure usually used in the literature.

\section{Results and discussions}

First trials to obtain pure poly (5-nitro-orthanilic acid) 2 failed and even if the reactants were stirred for $48 \mathrm{~h}$ produced only yellow precipitate contains an unreacted and probably dimeric mixture. Polymerization of aniline-2-sulfonic acid (orthanilic acid) was chemically achieved only at high pressure ${ }^{14}$ to give the targeted polyorthanilic acid. Typical oxidative polymerization of orthanilic acid is not possible due to the -I and steric hindrances effects of the $-\mathrm{SO}_{3} \mathrm{H}$ group ${ }^{15}$. In substrate 1 used in this investigation the presence of strong electron withdrawal effect exerted by the substituents $-\mathrm{SO}_{3} \mathrm{H}$ and $-\mathrm{NO}_{2}$ group inhibits the first initiating oxidation step. Therefore, using a little amount of aniline to initiate the polymerization reaction was our alternative ${ }^{16}$. The targeted poly (5-nitro-orthanilic acid) 2 was chemically prepared, according to standard procedure described in IUPAC technical report ${ }^{17}$, using 10 moles $\%$ aniline and ammonium persulfate as an oxidizing agent from the commercial 5-nitro-orthanilic acid $\mathbf{1}$ in low pH 1.5 aqueous $\mathrm{HCl}$ media, Scheme 1. Percentage yield $\left(52 \%, \eta_{\text {inh }}=0.10\right)$ was calculated by using the formula ${ }^{18}:[\%$ Polymer yield $=($ Weight of polymer $/$ Weight of substrate 1) $\mathrm{x}$ 100]. The reaction rate depends mainly on the reactivity of the reactant substrate as well as any hindrance to reaction propagation which greatly affects the yield. $\mathrm{The}-\mathrm{SO}_{3} \mathrm{H}$ and $-\mathrm{NO}_{2}$ substituents are present at the ortho and para positions with respect to the $-\mathrm{NH}_{2}$ group, respectively, would electronically direct the propagation taking place solely at the $\mathrm{C} 3$ position. During the propagation step, the ortho $-\mathrm{SO}_{3} \mathrm{H}$ group would reduce the nucleophilicity of the $-\mathrm{NH}_{2}$ group and also 
exerts a steric hindrance, nevertheless, further head-to-tail oxidative polymerization can be expected by the unsubstituted co-monomer aniline and thereby to fair polymerization yield. The postulated reaction mechanism is shown in Scheme 2.

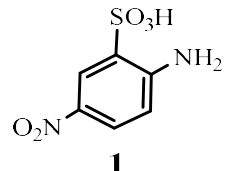

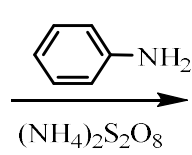

$\left(\mathrm{NH}_{4}\right)_{2} \mathrm{~S}_{2} \mathrm{O}_{8}$
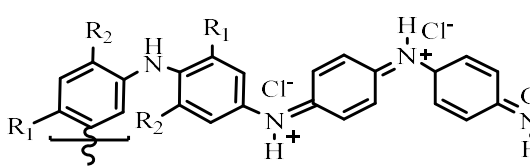

2

$\mathrm{R} 1=\mathrm{NO}_{2}, \mathrm{R} 2=\mathrm{SO}_{3} \mathrm{H}$

Scheme 1: Chemical synthesis of aniline-catalyzed poly (5-nitro-2-orthanilic acid)

The morphology of the synthesized polymers 2 investigated by SEM, Figure 1a, revealed that the polymer has a regular flower-leaf-like microstructure. However, the TEM image, Figure 1b, exhibited particle micro aggregates and clearly indicated the presence of both unsubstituted aniline units (dark nanospheres) and the substituted polymeric units (light gray micro aggregates). For comparison purposes, an SEM image of the product obtained from uncatalyzed polymerization trials is shown in Figure 1c. The morphology and the particles sizes are attributed to the nature of the substituent and thus the mechanism of the monomer unit's interactions ${ }^{19}$. The presence of monomer hydrophilic $-\mathrm{SO}_{3} \mathrm{H}$ group and a hydrophobic $-\mathrm{NO}_{2}$ on one aromatic ring gives the structure amphiphilicity or self-assembly nature, which are surrounded by the aromatic ring forming micelles ${ }^{20}$ and the aggregation of such small micelles produces submicron groups that are templates for such morphology found.
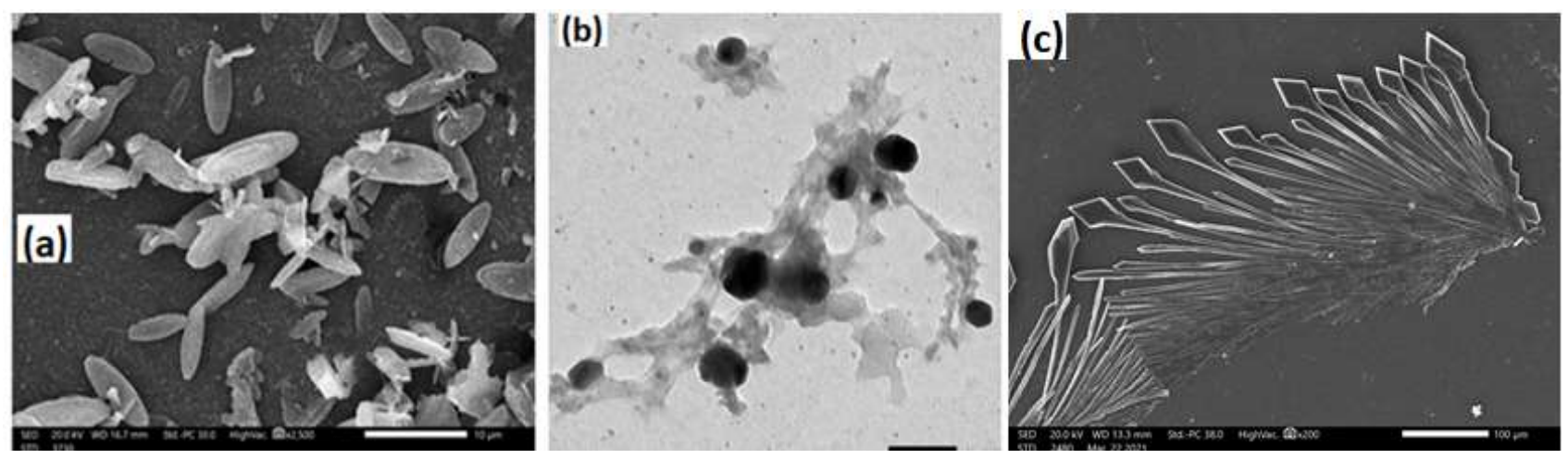

Figure 1: (a) SEM and (b) TEM images of the prepared Poly (5-nitro-orthanilic acid) 2 initiated by aniline. Figure 1 (c) SEM image of uncatalyzed polymerization product

\section{Elemental analysis}

The elemental compositions of polymer 2 was: $\mathrm{C}, 30.35 ; \mathrm{H}, 5.012 ; \mathrm{N}, 17.15 ; \mathrm{C} / \mathrm{N}$ ratio 1.76 [Calc. for $\mathrm{C}_{19} \mathrm{H}_{36} \mathrm{~N}_{9} \mathrm{~S}_{2} \mathrm{Cl}_{2}:(750)$; $\mathrm{C}, 30.31 ; \mathrm{H}, 5.05 ; \mathrm{N}, 16.82 ; \mathrm{S}, 8.55 ; \mathrm{Cl}, 9.46 ; \mathrm{C} / \mathrm{N}$ ratio 1.80$]$. Analysis of sulfur contents showed $11.40 \%$ and therefore the $\mathrm{S} / \mathrm{N}$ ratio $=0.66$ indicating a high content of substituted units in the resulted polymer backbone. The data for $\mathrm{C}$ and $\mathrm{N}$ are in good agreement with the chemical formula of a modified polyaniline backbone. The total amounts of carbon, hydrogen and nitrogen in the resulting polymer were $90.94 \%$, indicating the contamination of the polymer with chlorine and/or ammonia as speculated doped emeraldine salt forms ${ }^{21}$. This could be attributed to the presence of ammonium hydrogen sulfate that was not possible to fully wash out during the working up of the product. The ratio of $\mathrm{C} / \mathrm{N}$ was $1.76(\mathrm{Calc}$. 1.75) 
and agrees with the theoretically predicted values for their analogues ${ }^{22}$. Worthy to note, the elemental data also indicated that ammonium species were incorporated into the polymer product during the polymerization.

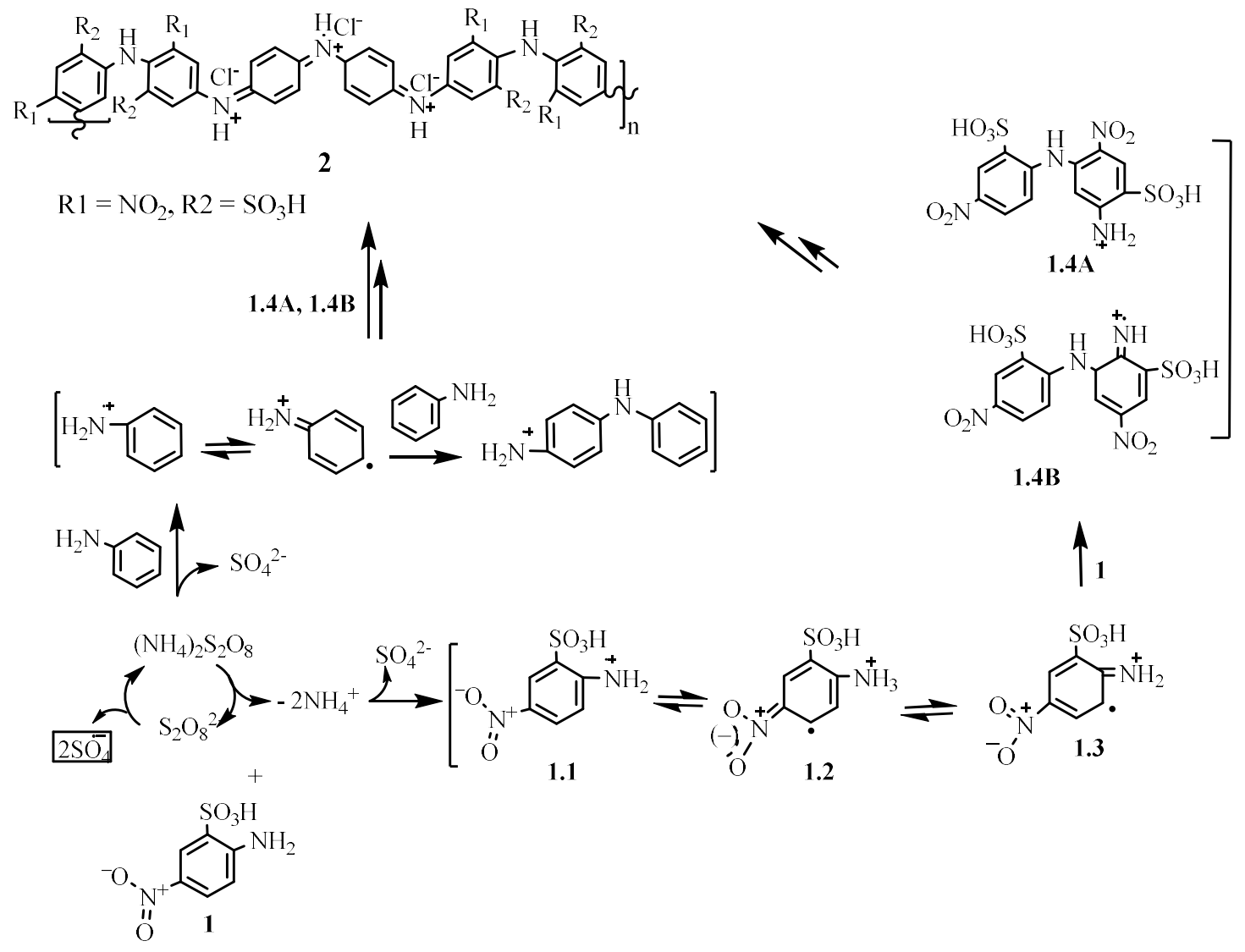

Scheme 2: Proposed formation mechanism of the polymer 2

\section{Infrared Spectroscopy}

The FTIR spectrum shows absorption at $v 3359-3425 \mathrm{~cm}^{-1}$ that corresponds to the $\mathrm{NH}_{\mathrm{vib}}$ bond, the peak in the region of $\mathrm{v}$ 2925-3000 cm-1 is due to the vibrations of the $\mathrm{C}-\mathrm{H}_{\text {arom }}$ bonds. A band at $2707 \mathrm{~cm}^{-1}$ suggests the existence of ammonium salts $^{22}$. Characteristic polymer structure peaks were found at $\mathrm{v} 1500$ and $1571 \mathrm{~cm}^{-1}$ corresponding to the vibrations of the benzenoid and quinoid moieties and their intensity ratio was 1.3, confirming the rapid equilibrium between the two forms ${ }^{23,24}$. The relative intensity of the quinoid / benzenoid bands reflects not only the degree of oxidation of the polymer chain $^{25}$, but also confirms the formation of bipolaron in the initial oxidation stage. The absorption bands at $v 1321 \mathrm{~cm}^{-1}$ and v $1254 \mathrm{~cm}^{-1}$ correspond to the $\mathrm{C}-\mathrm{N}$ and $\mathrm{C}-\mathrm{N}^{+}$stretching vibrations, respectively. The peak observed at $\mathrm{v} 1221 \mathrm{~cm}^{-1}$ corresponds to $\mathrm{N}=\mathrm{O}$ symmetric stretching vibration due to $\mathrm{NO}_{2}$ groups. The asymmetric stretching band of $\mathrm{N}=\mathrm{O}$ group was not observed and could be buried under the $\mathrm{C}-\mathrm{N}$ absorption. The presence of a peak at $\mathrm{v} 1074-1131 \mathrm{~cm}^{-1}$ indicates the doped state of the polymer $\left(-\mathrm{N}^{+} / \mathrm{N}^{+\cdot}\right)$. The absorption at $\mathrm{v} 828 \mathrm{~cm}^{-1}$ corresponds to the bending vibrations of C-H in plane of the aromatic ring. The S-O stretching band appeared at $v 748 \mathrm{~cm}^{-1}$, and the peak at $v 620 \mathrm{~cm}^{-1}$ is for the C-S stretching vibrational $^{26}$. 


\section{Ultraviolet-Visible Absorption Spectroscopy}

The bandgap energy is calculated from the equation: $\Delta \mathrm{E}=\mathrm{hc} / \lambda$, where $\Delta \mathrm{E}$ is band gab energy $(\mathrm{eV}), \mathrm{h}=6.625 \mathrm{x}$ 10-34 JS, $\mathrm{c}=3 \times 108 \mathrm{~m} / \mathrm{s}, \lambda$ is the wavelength. The electronic spectra of the substituted polymer 2 show absorption bands at $255 \mathrm{~nm}, 380 \mathrm{~nm}$ and their band gab energies were $4.86 \mathrm{eV}$ and $3.26 \mathrm{eV}$, respectively. The observed absorptions are assigned to bandgap and absorption data show bathochromic shifts. The increase in bandgap occurred because of increasing the torsion angle between C-N-C plane and the plane of the benzene ring, due to the electronic nature of the substituent and thus affecting the conjugation degree. Due to random substitution of the monomers of such polymerization, substituent causes entangling of polymer chains that disrupt the conjugation length that results in a hypsochromic shift of $\pi-\pi^{*}$ transition at $255 \mathrm{~nm}$ and polaron- $\pi *$ transition at $380 \mathrm{~nm}$, respectively.

\section{Cyclic voltammetry}

The electrochemical study of the substituted copolymer $\mathbf{2}$ obtained was conducted by measuring cyclic voltammogram, Figure 2. Polyaniline itself is known to be a redox polymer; therefore, incorporation of substituent into its structure affects the oxidation and reduction potentials observed on the cyclic voltammetry that are related to a change in its redox form. The cyclic voltammetry maxima correspond to transitions between the oxidation forms.

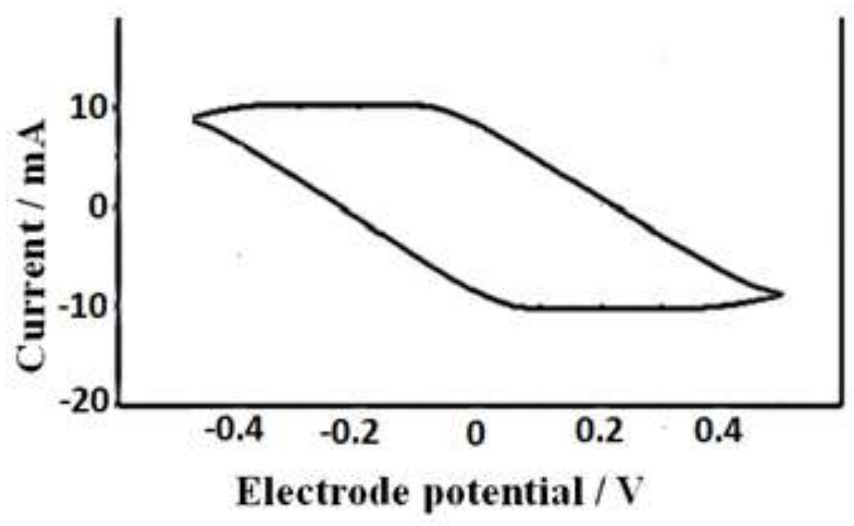

Figure 2: Cyclic voltammogram of substituted the prepared polymer 2. Scan rate of $100 \mathrm{mV}^{\mathrm{s}-1}$

Copolymer 2 was subjected to electrochemical tests to study the electron transferred behavior. The experiment (one cycle) was conducted at concentration $5 \mathrm{mg}$ in $20 \mathrm{ml}$ DMSO solution. The voltammogram wave shape showed only one broadly cathodic peak at $0.056 \mathrm{~V}$, assumed for the reduction of quinoid structure in the polymer chain, and one broadly anodic peak at $-0.090 \mathrm{~V}$, respectively. This electrochemical behavior could be attributed to the presence of electron-withdrawing, $-\mathrm{SO}_{3} \mathrm{H}$ and $-\mathrm{NO}_{2}$ groups which can be oxidized to quinone and vice versa at different potentials ${ }^{27}$, Figure 3 . The cyclic voltammogram of copolymer 2 exhibited good reversibility. 


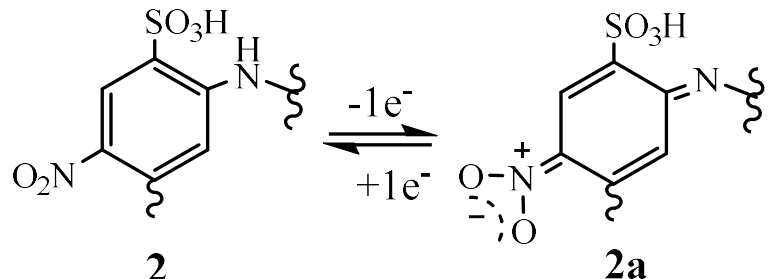

Figure 3: Reduced and resonating oxidized structures of the functionalized monomeric moiety in the copolymer 2

\section{Thermal analysis}

TG-DTG and DSC curves for the substituted polymer 2 are shown in Figure 4. The TGs thermal degradation curve, Figure 4a, exhibited an interesting model of the stability of the polymer and its subsequent weight-losses could be divided into four steps. The first minor one from rt to $198^{\circ} \mathrm{C}$ could be attributed to the loss of absorbed water. The second minor weight loss from $197^{\circ} \mathrm{C}-279^{\circ} \mathrm{C}$ is attributed to the loss of acid dopant from the polymeric matrix. The third weight loss (major peak) from $281^{\circ} \mathrm{C}-346^{\circ} \mathrm{C}$ (strong differential thermogravimetric endothermic peak at $292^{\circ} \mathrm{C}$ ) $345^{\circ} \mathrm{C}-466^{\circ} \mathrm{C}$ are likely due to decomposition and/or elimination processes of the side-chain substituents. The oxidative thermal decomposition of polymer backbones was suggested above $500^{\circ} \mathrm{C}$ for the polymeric remaining residues $(31 \%)$ as final weight loss. In the DSC curve, Figure $4 \mathrm{~b}$ the polymer shows a strong exothermic peak of energy $690.18 \mathrm{~J} / \mathrm{g}$ at $292^{\circ} \mathrm{C}$, as well as a strong endothermic peak at $305^{\circ} \mathrm{C}$, which corresponds to decomposition or elimination processes of the side-chain substituents and the subsequent morphological change in the polymer ${ }^{28}$. The glass temperature $(\mathrm{Tg})$ of the polymer was observed at $240^{\circ} \mathrm{C}$.

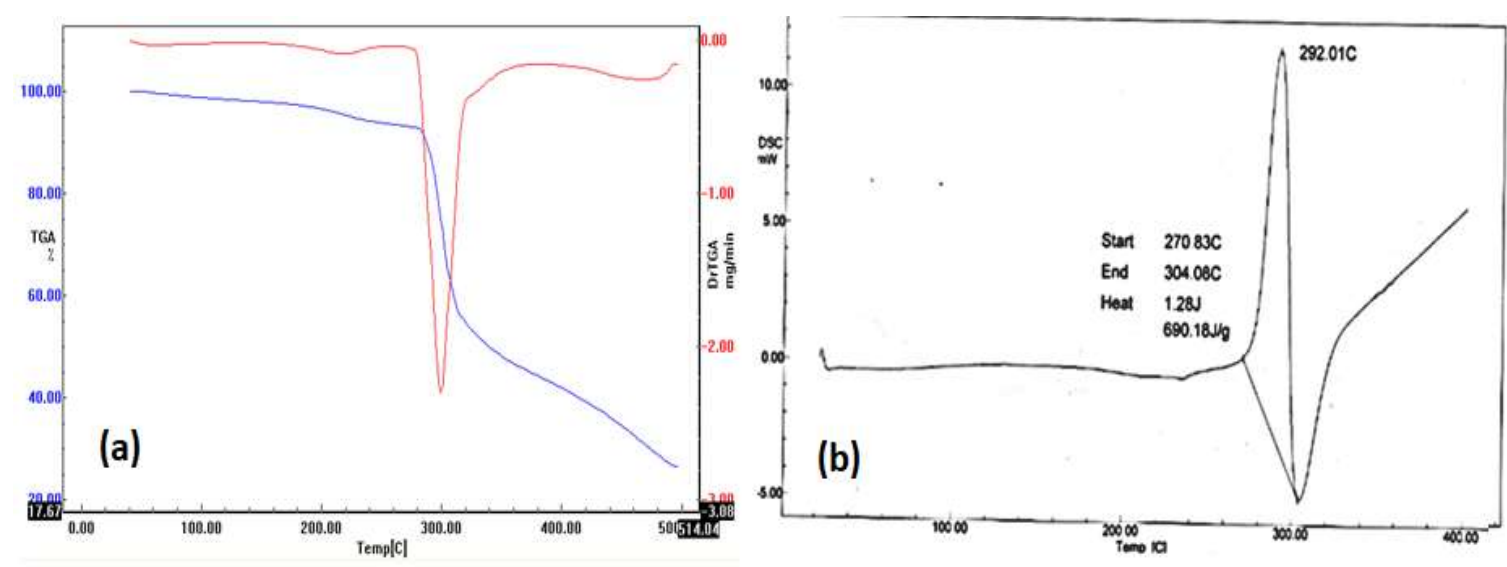

Figure 4: (a) TG-DTG and (b) DSC thermograms of the substituted polymer 2

\section{Electrical Conductivity}

\section{Dielectric measurements}

The dielectric measurements carried out using a high analyzer technique could probe molecular fluctuations and charge transport in broad frequency and temperature ranges. The dielectric spectrum is separated to molecular dynamics at the molecular scale, i.e., charge carriers' transport, which is reflected in conductivity mechanisms. The permittivity $\left(\varepsilon^{*}\right)$ is the measure of resistance that is developed upon generating an electric field in a particular substance. The permittivity $\left(\varepsilon^{*}\right)$ was determined at five-spot frequency points and depicted against temperatures in the range of $40^{\circ} \mathrm{C}$ to $100^{\circ} \mathrm{C}$ for the substituted polymer 2, Figure 5. In general, two distinguished trends of the real part of complex permittivity $\varepsilon^{\prime}$ vs frequency could be 
assigned. The lower frequency range $(0.1 \mathrm{~Hz}-10 \mathrm{kHz})$ shows a gradual decrease of $\varepsilon^{\prime}$ through six orders of magnitudes, mainly due to the charge carriers' transport causing expected high conductivity. At a higher range of frequencies $(10 \mathrm{kHz}-20 \mathrm{MHz})$, a slight effect was observed for frequency on decreasing the permittivity. This effect agrees with the fact that at higher frequencies, the contribution of the alteration of all kinds of polarizations lags the frequency of the applied external electric field ${ }^{29}$.

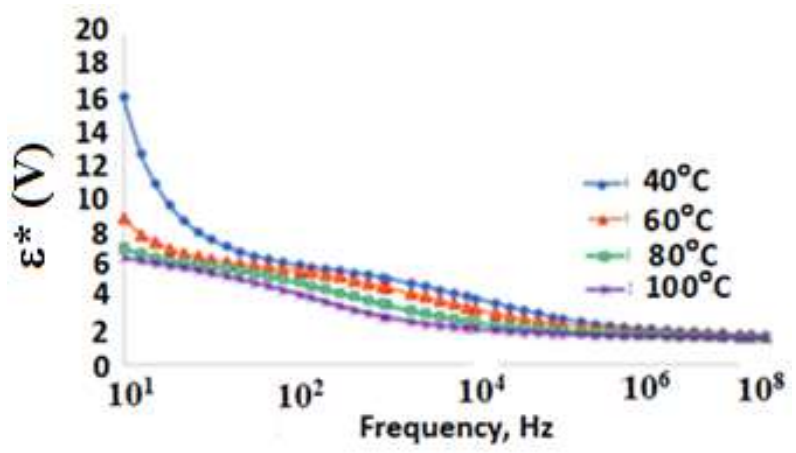

Figure 5: Effect of temperature on permittivity $\left(\varepsilon^{*}\right)$ at different frequency for the polymer 2

The variation of conductivity $\sigma^{\prime}$ vs frequency (DC-conductivity) and the dissipation factor tan $\delta$ vs frequency at a temperature ranging $\left(40^{\circ} \mathrm{C}-100^{\circ} \mathrm{C}\right)$ are illustrated graphically in Figures $6 \mathrm{a}$ and $6 \mathrm{~b}$ for polymer 2 , respectively. Figures show a clear sharp peak followed by a small shoulder at lower limit points of frequency. At higher frequencies, it follows the power law: $\left[\sigma^{\prime}(\omega)=\mathrm{A} \omega^{5}\right]$, in which $\mathrm{A}$ is constant and s characterizes the rate of change of AC-conductivity with increasing frequency. The intermediate range of frequency shows a plateau-like behavior that represents the dcconductivity, $\sigma \mathrm{dc}$. It is affected vary slightly between 1 and $2 \mathrm{mS} / \mathrm{cm}$ by the variation of the irradiation dose, which confirms the fact that the contribution of the conductivity plays the main role of the permittivity values at the lower frequencies. The accumulation of charge carriers is the origin of the electrode polarization, the ubiquitous phenomenon which takes place at the interface between a metallic and an ionic conductor and thus, increases by many orders of magnitude the net dielectric response of the sample cell. Since Coulombic interactions take place here, ion mobility is drastically slowed down at the interfaces.
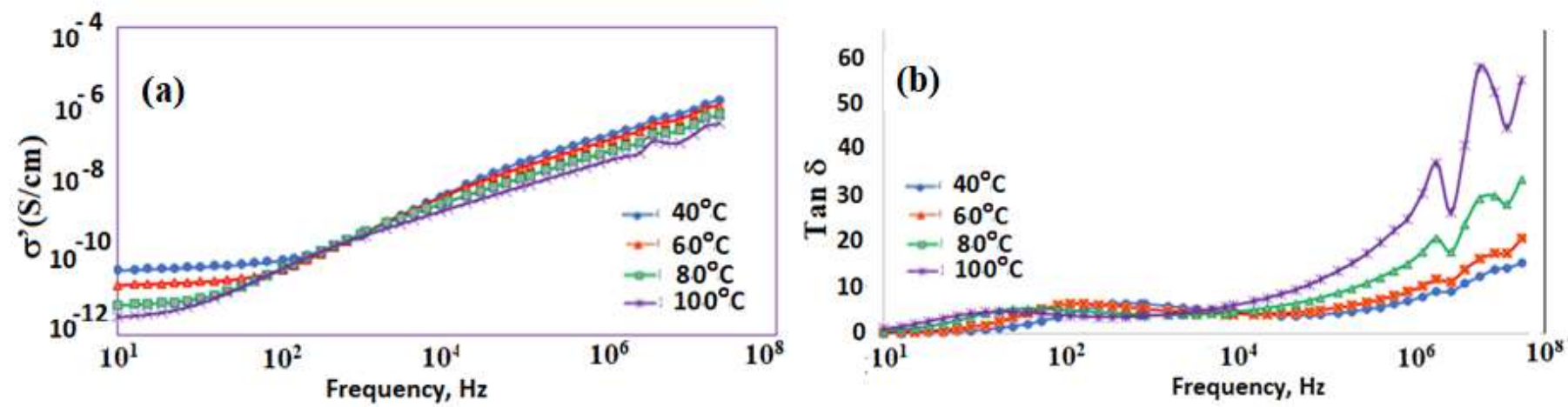

Figure 6: a) Conductivity $\left(\sigma^{\circ}\right)$ vs frequency- and b) Dissipation factor $(\tan \delta)$ vs frequency for polymer 2 at temperature range $40{ }^{\circ} \mathrm{C}-100{ }^{\circ} \mathrm{C}$ 
Figure 7 illustrates the effect of temperature on the conductivity $\sigma$ ' and dielectric constant $\varepsilon$ ' plotted at different frequencies (i.e., $100 \mathrm{~Hz}, 10$, and $100 \mathrm{kHz}$ ) for the polymers 2 . In Figure $7 \mathrm{a}$, as the temperature increases, the conductivity decreases at different applied frequencies. This behavior is indicative of semiconducting nature in the extrinsic range, which is characterized by high carriers and low mobility. The main two factors affecting the value of conductivity are the density of the charge carriers, $n$, and their mobility, $\mu$. The Charge density and mobility as a function of temperature, which the effect of the change of charge density only plays a limited role in the variation of the DC conductivity. This can be attributed to the fluctuation dynamics of the accumulated charge carriers at the interface. These fluctuation dynamics seem to be the reason for the asymmetric wing of the $\sigma^{\prime \prime}$ peak at lower frequencies which is accompanied by a shoulder in the tan $\delta$ and deviation from linearity of conductivity decrease shown in Figure $7 \mathrm{a}^{30}$. The low conductivity of the copolymer 2 could be explained by both the reduced conjugation length in distorted chains and the decrease in interchain charge transport induced by bulky $\mathrm{SO}_{3} \mathrm{H}$ groups, and the electrostatic interactions between the sulfonate functional groups and main-chain cationic nitrogen or amine's hydrogens. The study of dielectric constant as a function of temperature and frequencies is one of the most convenient methods of studying the molecular orientation behavior and associated relaxation mechanism of polymer structure $^{31}$. In Figure 7b, the dielectric constant decreases with increasing frequencies. At higher frequencies, the value of the dielectric constant nearly steadily decreases. However, at low frequency, the dielectric constant decreases between $\left(20^{\circ} \mathrm{C}-40^{\circ} \mathrm{C}\right)$ temperature range, then maintain stable between $\left(40^{\circ} \mathrm{C}-60^{\circ} \mathrm{C}\right)$ range and then continue decreasing. This nature is not observed at higher frequencies. The low-temperature dielectric dispersion is attributed to the dielectric response of the side groups which are more mobile or the small displacement of the dipoles near the frozen-in position and known as the secondary dispersion region or B-relaxation ${ }^{32}$.
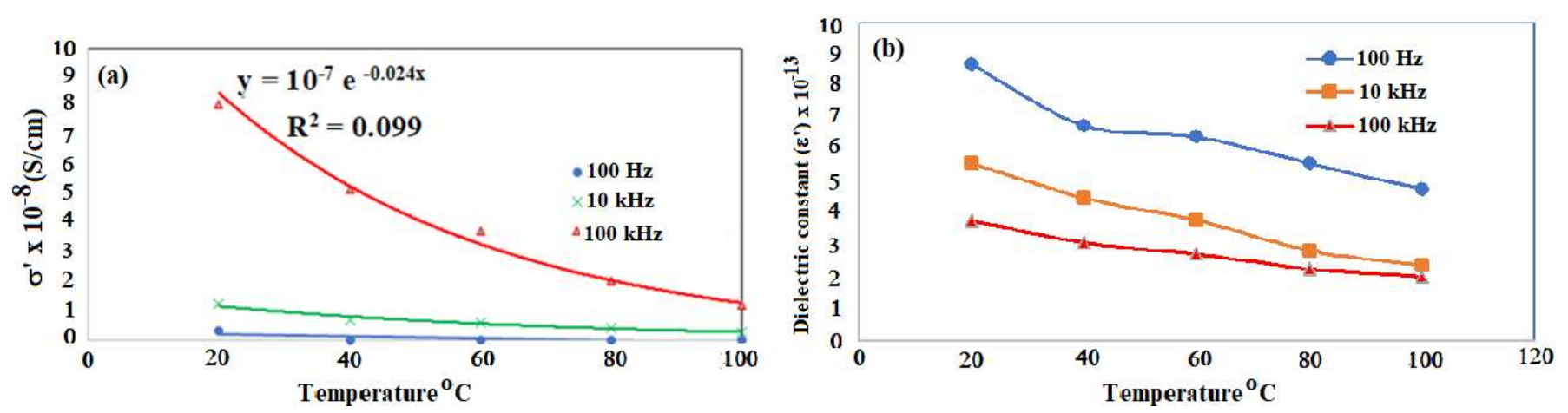
Figure 7: The variation of: (a) conductivity $\left(\sigma^{\prime}\right)$ and (b) dielectric constant $\left(\varepsilon^{\prime}\right)$ vs Temperature
for the polymer 2 at $100 \mathrm{~Hz}, 10 \mathrm{KHz}$ and $100 \mathrm{KHz}$ frequencies

\section{Assessment of the copolymer 2 as precipitation inhibitor of $\mathrm{CaCO}_{3}$ and $\mathrm{CaSO}_{4}$ in solution}

\section{Effect of copolymer 2 on $\mathrm{CaSO}_{4}$ precipitation}

To examine the synthesized copolymer 2 as new scale inhibitors of $\mathrm{CaSO}_{4}$, free calcium ions concentration was determined according to the NACE test in the absence and the presence of different polymer concentrations (ppm), and the results are compiled in Table 1. The concentration of free $\mathrm{Ca}^{+2}$ ions slightly increased with increasing polymer concentration, indicating inhibition of the calcium sulfate precipitation process. In the literature, the inhibition of the $\mathrm{CaSO}_{4}$ scale by inhibitor-containing sulfonate groups is usually explained by the interaction of calcium cations present 
in solution with sulfonate groups through $\mathrm{Ca} \ldots . . \mathrm{SO}_{3}$ interaction and thereby blocks crystal growth ${ }^{13 a}$. In general, while $\mathrm{M}-$ $\mathrm{O}$ interaction is weak in a single sulfonate moiety, each oxygen atom has the potential to bridge more than one metal center, and typically, the oxygen atoms of an $\mathrm{SO}^{3-}$ moiety will bridge a maximum to two metal ions ${ }^{33}$. The limited $\mathrm{CaSO}_{4}$ inhibition efficiency by polymer $\mathbf{2}$ is attributed, most probably, due to a change in polymer geometry because of the expected intramolecular hydrogen bonding interaction of the ortho-sulfonic group and the polymer chain in an aqueous medium, Figure 8, and thus retards the speculated calcium-sulfonate interaction.<smiles>[Y]c1cc2c(cc1[N+](=O)[O-])N(S(=O)(=O)Cl)[IH]OS2(=O)=O</smiles>

Figure 8: Proposed intramolecular interaction of the ortho-sulfonic group and the polymeric chain

\begin{tabular}{|l|l|l|}
\hline $\begin{array}{c}\text { Polymer } \\
\text { concentration } \\
\text { (ppm) }\end{array}$ & $\begin{array}{c}\mathrm{Ca}^{2+} \\
\mathbf{p p m}\end{array}$ & $\begin{array}{c}\% \\
\text { Inhibition }\end{array}$ \\
\hline 10 & 900.90 & 24 \\
\hline 50 & 920.92 & 29 \\
\hline 100 & 960.96 & 38 \\
\hline \hline
\end{tabular}

Table 1: Concentration of free $\mathrm{Ca}^{+2}$ ion in brine in the absence and presence of different concentrations of polymer 2 and their percent of inhibition, $\left(C_{b}=1221.22 \mathrm{ppm}\right.$ and $\left.C_{a}=800.8 \mathrm{ppm}\right)$

\section{Effect of copolymer 2 on $\mathrm{CaCO}_{3}$ precipitation}

\section{Chronoamperometry measurements:}

The buildup of the calcium carbonate layer on the metal surface is illustrated in Figure 9. As shown, the Chronoamperometry curve of the polarized steel electrode in the absence of the polymer decreases sharply, indicating to the fast formation of $\mathrm{CaCO}_{3}$ crystals which occupied parts of the steel surface and consequently decreases the current density. On the other hand, the addition of an inhibitor to the brine solution delays the scaling process and increases the residual current on the steel surface. Increasing the concentration of the polymer increases residual current values for steel electrode after polarization from $44 \mu \mathrm{A}$ for a blank solution to $140 \mu \mathrm{A}$ in presence of $150 \mathrm{ppm}$ of the polymer, Figure 10 . Usually, the current density is inversely proportional to the quantity of $\mathrm{CaCO}_{3}$ scales formed on the metal surface. Thus, the observed inhibition order indicated that the presence of copolymer 2 significantly inhibits carbonate scale formation. 


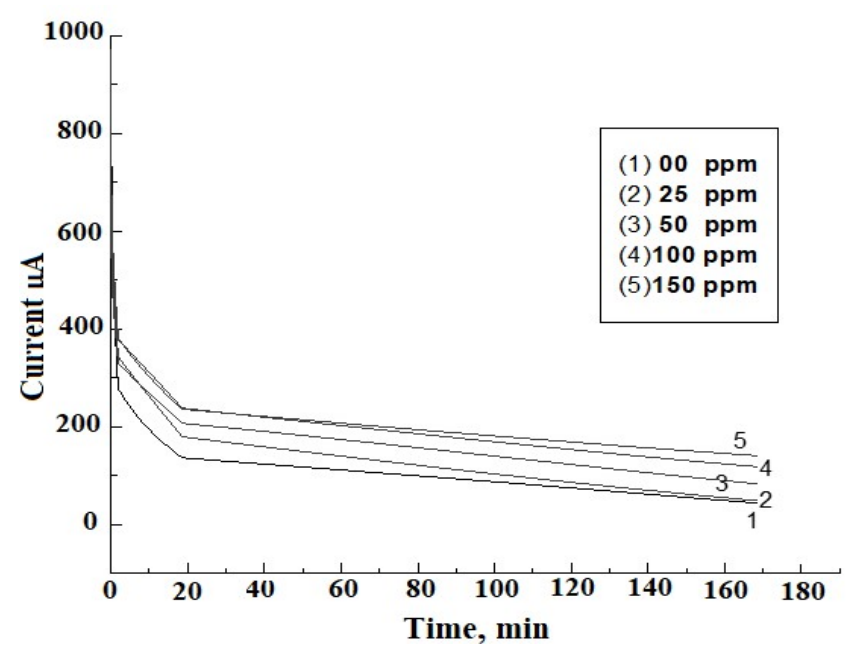

Figure 9: Chronoamperometry curves for polarized steel electrode in $\mathrm{CaCl}_{2}$ brine solution in the absence and presence of different concentrations of studied polymer at $-1 \mathrm{~V}$ vs $\mathrm{SCE}$ and $40^{\circ} \mathrm{C}$.

\section{Electrochemical Impedance Measurements:}

Figure 11 represents Nyquist plots for steel after cathodic polarization in a brine solution in the absence and presence of different concentrations of copolymer 2. The impedance spectra of the polymer show a typical feature of depressed semicircles followed by a low-frequency tail. The size of distorted semicircles decreases in the presence of the polymer due to the behavior of the double layer that led to a decrease in the charge transfer resistance due to the reduction of the insulation layer of the scale ${ }^{13 a}$. The equivalent circuit, Figure 12, that was used to fit the experimental data of impedance plots for the scale formation processes in brine solution was illustrated in Figures 13 and 14.

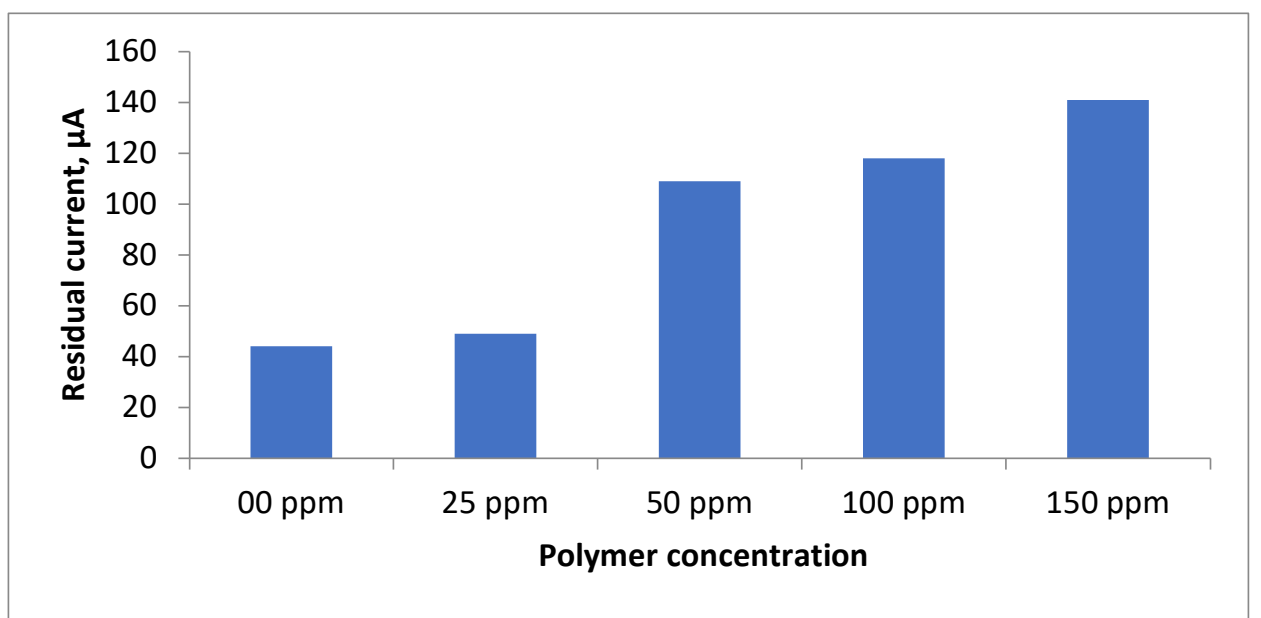

Figure 10: Variation of residual current for steel electrode after $3 \mathrm{~h}$ of polarization in $\mathrm{CaCl}_{2}$ brine solution in in the absence and presence of different concentrations of studied polymer at $-1 \mathrm{~V}$ vs SCE and $40^{\circ} \mathrm{C}$. 


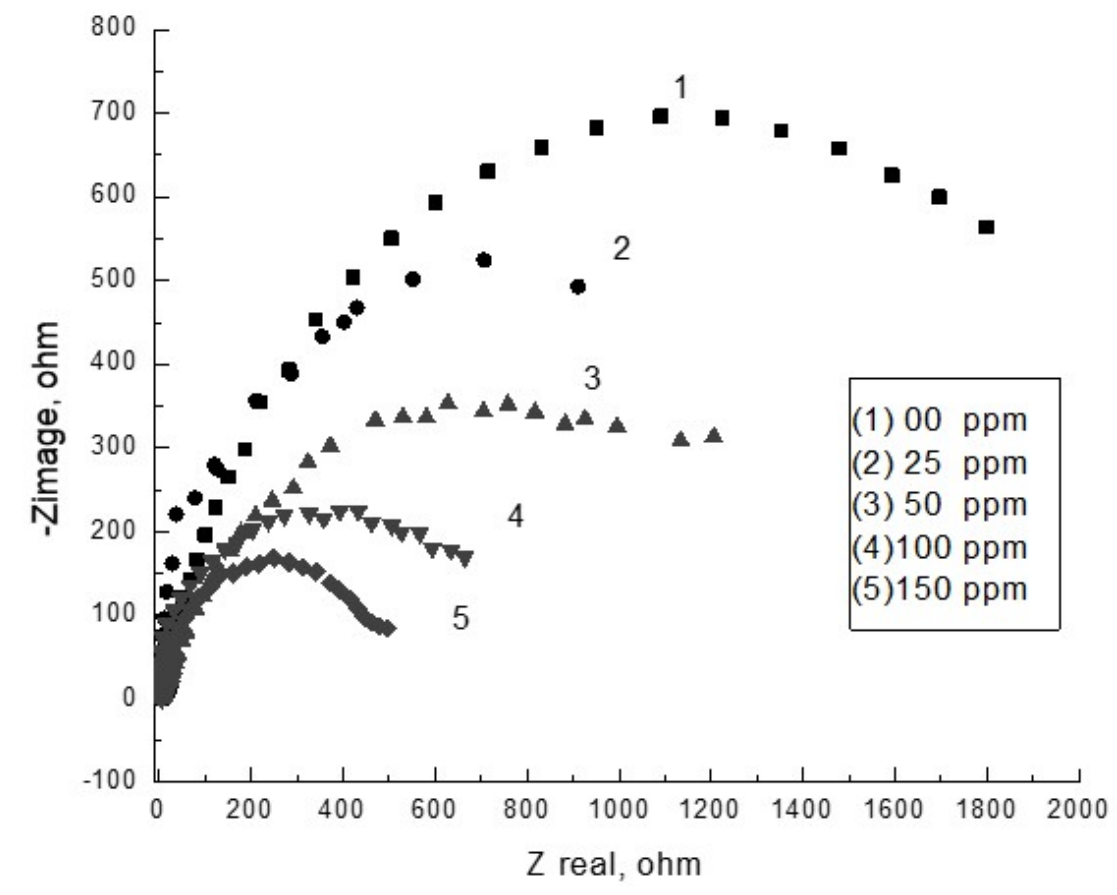

Figure 11: Impedance spectra of polarized steel in brine solution in the absence and presence of different concentrations of the copolymer 2 at $40{ }^{\circ} \mathrm{C}$

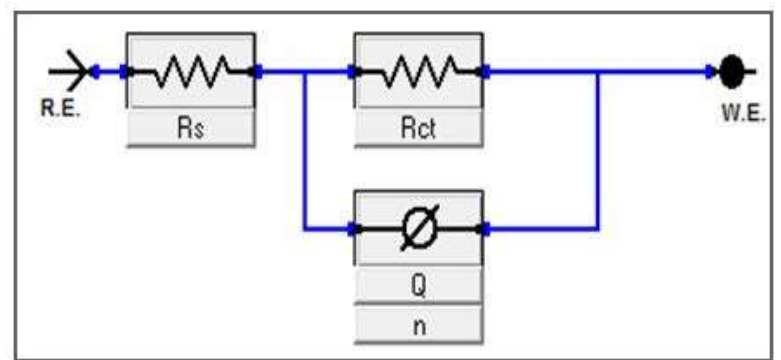

Figure 12: Schematic for the equivalent circuit models used to determine the impedance Parameters for scale process in the $\mathrm{CaCl}_{2}$ brine solution.

( $R_{s}$; the solution resistance, $R_{c t}$; the charge transfer resistance, $Q$; is associated to the double-layer capacitance)

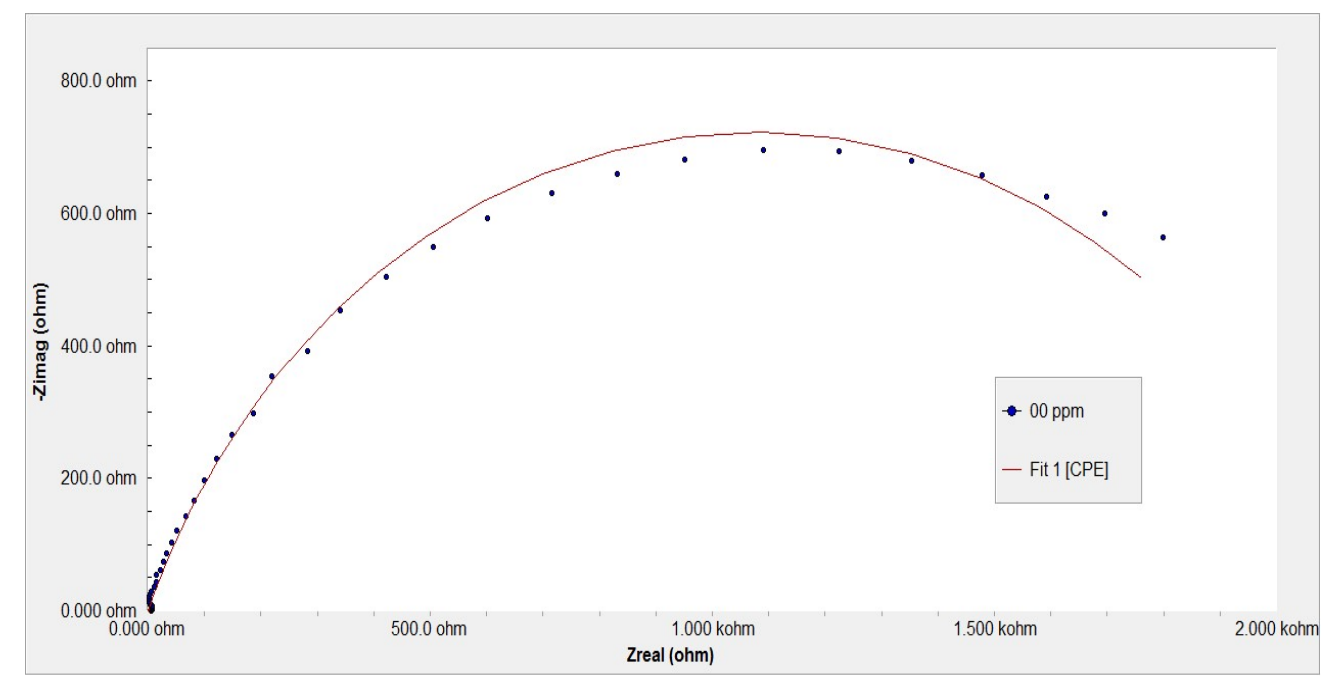

Figure 13: Impedance spectra of polarized steel in brine solution with its fitting curves and equivalent circuits in the absence and presence of scale inhibitors 


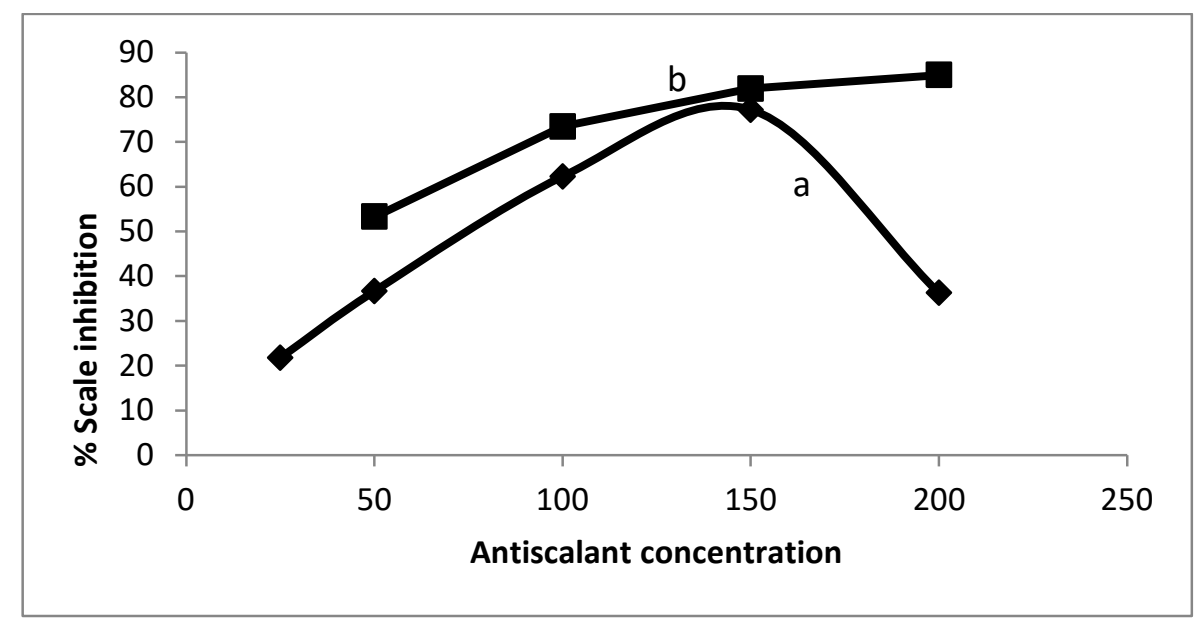

Figure 14: Variation of \% $\mathrm{CaCO}_{3}$ inhibition with different concentration of:

(a) Oxidation product of substrate 1 without addition of aniline initiator

(b) Copolymer 2

Table 2 shows Computer fit results of the impedance spectra obtained for the steel electrode that was cathodically polarized in the $\mathrm{CaCl}_{2}$ brine solution containing different concentrations of the polymer after 3 hours. The percentage of scale inhibition could be determined from the following equation: \% scale inhibition $=\left[\left(\mathrm{Rct}_{\mathrm{o}}-\mathrm{Rct}_{\mathrm{i}}\right) / \mathrm{Rct}_{\mathrm{o}}\right] \mathrm{x} 100{ }^{19 \mathrm{a}}$ where $(\mathrm{Rct})_{\mathrm{o}}$ and $(\mathrm{Rct})_{\mathrm{i}}$ are charge transfer resistances after polarizing the steel electrode at $-1 \mathrm{~V}$ (vs. SCE) in scaling environment for 3 $\mathrm{h}$ in the absence and presence of the polymer, respectively. The results indicated that the increasing concentration up to 50 ppm resulted in a decrease in the charge transfer resistance Rct, which is inversely proportional to the formation of scale. Also, presence of the polymer increased the non-ideal film capacitance values, Q, due to the formation of the double layer which reduce the formation of the insulating layer on the metal surface. Further increasing of the polymer concentration decreases the non-ideal film capacitance because of an increase in the thickness of the electrical double layer associated to presence of polymer molecules which increase charge density near metal surface as well as decrease the efficiency of the polymer due to steric effect of high molecular weight polymer.

\begin{tabular}{|cccccc|}
\hline $\begin{array}{c}\text { Conc } \\
\text { (ppm) }\end{array}$ & $\begin{array}{c}\mathbf{R}_{\mathbf{s}} \\
\text { ohm.cm }\end{array}$ & $\begin{array}{c}\mathbf{Q} \\
\mathbf{H F}\end{array}$ & $\mathbf{n}$ & $\begin{array}{c}\mathbf{R}_{\mathbf{c t}} \\
\mathbf{O h m . c m}^{\mathbf{2}}\end{array}$ & $\begin{array}{c}\% \\
\text { Inhibition }\end{array}$ \\
0 & $5.03 \pm 0.04$ & $209.3 \pm 1.15$ & 0.79 & $2017 \pm 23.5$ & ------- \\
25 & $17.0 \pm 0.14$ & $60.13 \pm 0.77$ & 0.78 & $1577 \pm 18.4$ & $21.8 \%$ \\
50 & $6.8 \pm 0.06$ & $182 \pm 2.8$ & 0.68 & $1276 \pm 14.2$ & $36.7 \%$ \\
100 & $1.17 \pm 0.039$ & $358.2 \pm 2.3$ & 0.79 & $761.9 \pm 11.3$ & $62.3 \%$ \\
150 & $29.7 \pm 0.028$ & $361 \pm 2.2$ & 0.87 & $460.3 \pm 4.2$ & $77.2 \%$ \\
200 & $8.0 \pm 0.048$ & $307 \pm 1.9$ & 0.75 & $1285 \pm 14.9$ & $36.3 \%$ \\
\hline
\end{tabular}

Table 2: Computer fit results of the impedance spectra obtained for the steel electrode that was cathodically polarized in $\mathrm{CaCl}_{2}$ brine solution containing different concentrations of copolymer 2 after $3 \mathrm{~h}$ 
SEM images of $\mathrm{CaCO}_{3}$ crystals after direct precipitation are displayed in Figure 15. The cubic structure of calcium carbonate crystals is observed in absence of antiscalants. A low degree of crystals modification was observed in presence of the polymer, which may be due to change in polymer geometry because of the expected intramolecular hydrogen bonding interaction of the ortho-sulfonic group and the polymer chain in an aqueous medium and thus retards the speculated calciumsulfonate interaction which facilitates the attachment of polymer molecules on the metal surface and hinders crystal attachment.

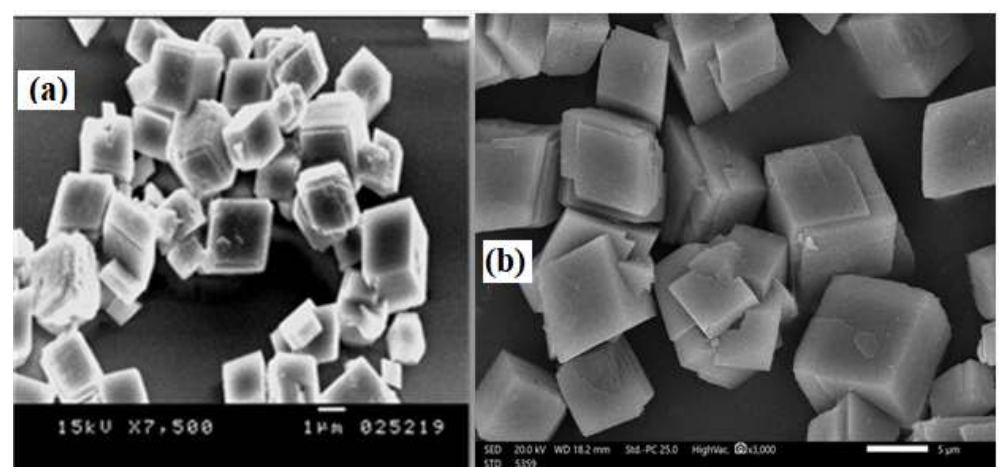

Figure 15: SEM images of $\mathrm{CaCO}_{3}$ crystals: (a) in absence, and (b) in presence of copolymer 2

\section{Materials and methods}

Chemicals. The commercial aniline (AlGomhoria Chemicals Co.), 5-nitro-2-aminobenzenesulfonic acid (Aldrich), ammonium persulfate, double distilled water, analytical reagent-grade $\mathrm{NaCl}, \mathrm{NaHCO}, \mathrm{Na}_{2} \mathrm{SO}_{4}$ and $\mathrm{CaCl}_{2}(\mathrm{Al}-\mathrm{Gomhorya}$ Chemicals Co., Egypt) were used without further purification.

Measurements. Infrared spectra (IR, $\mathrm{KBr}$ pellets; $3 \mathrm{~mm}$ thickness) were recorded on a Perkin-Elmer Infrared Spectrophotometer (FTIR 1650). All spectra were recorded within the wave number range of $4000-600 \mathrm{~cm}^{-1}$ at $25^{\circ} \mathrm{C}$. Absorption spectra were measured with a UV $500 \mathrm{UV}$-Vis spectrometer at room temperature (rt) in DMSO with a polymer concentration of $2 \mathrm{mg} / 10 \mathrm{~mL}$. Elemental analysis of as-synthesized copolymer was performed at the Microanalytical Unit, Cairo University. The sulfur content was determined by ASTM-D1552 technique at Middle East Oil Refinery Company (Midor), Alexandria, Egypt. Inherent viscosities ( $\eta_{\text {inh }}$ ) were measured at a concentration of $0.5 \mathrm{~g} / \mathrm{dL}$ in $\mathrm{H}_{2} \mathrm{SO}_{4}$ at $30{ }^{\circ} \mathrm{C}$ by using an Ubbelohde viscometer. Thermogravimetric (TG) and differential thermogravimetric (DTG) analyses were carried out in the temperature range from $20{ }^{\circ} \mathrm{C}$ to $400{ }^{\circ} \mathrm{C}$ in a steam of nitrogen atmosphere by Shimadzu DTG $60 \mathrm{H}$ thermal analyzer. The experimental conditions were platinum crucible, nitrogen atmosphere with a $30 \mathrm{~mL} / \mathrm{min}$ flow rate and a heating rate10 C/min. Differential scanning calorimetry (DSC-TGA) analyses were carried out using SDT-Q600-V20.5Build-15 at the microanalytical unit, Cairo University. Cyclic voltammetry was performed using an eDAQ system (www.eDAQ.com), consisting of an E190 potentiostat connected to an e-corder which inputted to eChem software (running on a PC using Microsoft Windows 10). The working electrode was a $3 \mathrm{~mm}$ diameter glassy carbon electrode; the reference electrode was $\mathrm{Ag} / \mathrm{AgCl}$; the auxiliary electrode was a $0.25 \mathrm{~mm}$ diameter Pt wire. Applied potentials ranged from -500 to $+500 \mathrm{mV}$, and the scan rate was $100 \mathrm{mV} \mathrm{s}^{-1}$ The volume of the voltametric cell was approximately $15 \mathrm{ml}$. The dielectric 
measurements of the polymeric materials were carried out using a high-resolution Alpha analyzer (Novo Control, Hundsangen, Germany) in parallel plate geometry over a frequency range from $10^{-1} \mathrm{~Hz}$ to $10^{7} \mathrm{~Hz}$ at different range of temperatures. In this geometry, the sample cell consists of two gold-coated brass disk electrodes. The upper one is $10 \mathrm{~mm}$ and the lower one is $20 \mathrm{~mm}$ diameter. The pressed sample with $12 \mathrm{~mm}$ diameter was sandwiched between the two electrodes. The applied voltage was kept constant at $0.2 \mathrm{~V}$ to avoid any nonlinear effects. The empty sample capacitor is used as a reference to eliminate the additional contributions of the cables and the measurement cell. The temperature of the sample is controlled by a Quattro Novo control cryo-system with temperature stability better than $0.2 \mathrm{~K}$, as described in references ${ }^{34}$. The polymer powder was pressed to form discs of diameter $10 \mathrm{~mm}$ and thickness $1 \mathrm{~mm}$. silver electrodes were deposited on both sides of the sample surface by thermal evaporation and two copper wires were fixed on the sample using conducting silver paint. The morphologies of polymers morphologies were observed by Scanning Electron Microscope (SEM) (JEOLJSMIT 200) and Transmission Electron Microscopy (TEM) (JEOL-JTM-1400 plus), at the E-Microscope Unit, Faculty of Science, Alexandria University. The samples were sonicated in de-ionized water for $5 \mathrm{~min}$ and deposited onto carbon-coated copper mesh and allowed to air-dry before examination.

Synthesis of poly (5-nitro-orthanilic acid) 2. 5-Nitro-orthanilic acid 1 (5 g, $22.93 \mathrm{mmol})$ and aniline $(0.5 \mathrm{~g}, 5.37 \mathrm{mmol}$; $10 \mathrm{~mol} \%$ of $\mathbf{1})$ were dissolved in aqueous $1 \mathrm{M} \mathrm{HCl}(100 \mathrm{ml})$ and a solution of ammonium persulphate $(6.53 \mathrm{~g}, 28.65 \mathrm{mmol}$, $1.25 \mathrm{x})$ dissolved in water $(50 \mathrm{ml})$ was subsequently added over a period of $30 \mathrm{~min}$. The mixture was mechanically stirred for $24 \mathrm{~h}$ at $\mathrm{rt}$ and the color change pattern during polymerization from yellow to light, then dark green to brownish black was observed from $\mathrm{t}=10 \mathrm{~min}$ to $24 \mathrm{~h}$. Polymerization was stopped by addition of methanol $(50 \mathrm{ml})$. The resulting precipitate was subsequently washed with water, aqueous $1 \mathrm{M} \mathrm{HCl}$, water and acetone to remove the unreacted starting materials and short oligomers. Finally, the deep brown precipitate was dried in a vacuum oven at $50^{\circ} \mathrm{C}$. Yield: $2.6 \mathrm{~g}(52 \%)$. IR $\left(\mathrm{cm}^{-1}, \mathrm{v}\right)$ : $3434,3346,3247,1789,1642,1606,1571,1500,1481,1406,1321,1254,1221,1131,1074,1018,918,828,748,648,620$, 573, 516. UV-vis $\left(\lambda_{\max } \mathrm{nm}\right): 255,380$. Calc. for $\mathrm{C}_{19} \mathrm{H}_{36} \mathrm{~N}_{9} \mathrm{~S}_{2} \mathrm{Cl}_{2}:(750) ; \mathrm{C}, 30.31 ; \mathrm{H}, 5.05 ; \mathrm{N}, 16.82 ; \mathrm{S}, 8.55 ; \mathrm{C} / \mathrm{N}$ ratio 1.80 ; Found: C, 30.35; H, 5.012; N, 17.15; C/N ratio 1.76. Sulfur content found: $11.40 ; \mathrm{S} / \mathrm{N}$ ratio 0.66

\section{Determination of scale inhibitor rate}

NACE test for $\mathrm{CaSO}_{4}$ Scaling. Following the reported method described previously ${ }^{35}$, calcium brine: $7.5 \mathrm{~g} / \mathrm{L} \mathrm{NaCl}+11.0$ $\mathrm{g} / \mathrm{L} \mathrm{CaCl}_{2} .2 \mathrm{H}_{2} \mathrm{O}$ and Sulfate brine: $7.5 \mathrm{~g} / \mathrm{L} \mathrm{NaCl}+10.66 \mathrm{~g} / \mathrm{L} \mathrm{NaSO}_{4}, 50 \mathrm{ml}$ of each brine solutions were connected in the test cell with different concentration of sodium alginate and chitosan. Testing cells were placed in the water bath set at $71^{\circ} \mathrm{C}$ for $72 \mathrm{~h}$. Then, the concentration level of calcium ions was determined in the solution by titration with EDTA and Murexide indicator. The scale inhibitor percent was calculated following the equation: \% inhibition $=100 \times\left(C_{a}-C_{b}\right) /\left(C_{c}-\right.$ $\mathrm{C}_{\mathrm{b}}$ ), where $\mathrm{C}_{\mathrm{a}}=\mathrm{Ca}^{2+}$ concentration in the treated sample after precipitation, $\mathrm{C}_{\mathrm{b}}=\mathrm{Ca}^{2+}$ concentration in the blank after precipitation and $\mathrm{C}_{\mathrm{c}}=\mathrm{Ca}^{2+}$ concentration in the blank before precipitation.

\section{Electrochemical test for $\mathrm{CaCO}_{3}$ scaling}

Monitoring the buildup of calcium carbonate layers on the metal surface was studied by the electrochemical method including chronoamperometry and electrochemical impedance spectroscopy ${ }^{13 a}$. 
Chronoamperometry test. Cathodic polarization of steel electrode initializes scaling process by forcing few nuclei of $\mathrm{CaCO}_{3}$ to be precipitated on steel surface according to the following equations:

$$
\begin{aligned}
& \mathrm{O}_{2}+2 \mathrm{H}_{2} \mathrm{O}+4 e^{-} \rightarrow 4 \mathrm{OH}^{-} \\
& \mathrm{Ca}^{2+}+\mathrm{HCO}_{3}^{-}+\mathrm{OH}^{-} \rightarrow \mathrm{CaCO}_{3}+\mathrm{H}_{2} \mathrm{O}
\end{aligned}
$$

In chronoamperometry test, cathodic polarization was applied to steel electrode surface which increases the local $\mathrm{pH}$ at the cathode as illustrated in equation 1, while increasing the hydroxyl ion concentration enables calcium carbonate to precipitate as given in equation 2. The electrochemical measurements were carried out in a cell with three-electrode mode using platinum sheet and saturated calomel electrode (SCE) as counter and reference electrodes, respectively. The material used for constructing the working electrode was steel that had the following chemical composition (wt.\%): $\mathrm{C}, 0.21 ; \mathrm{S}, 0.04 ; \mathrm{Mn}$, 2.5; P, 0.04; Si, 0.35; balance Fe. Steel electrode was polarized to $-1.0 \mathrm{~V}$ (vs. SCE) in test solution in absence and presence of different concentrations of polymer 2 for $3 \mathrm{~h}$ using Gamery instrument G300 ${ }^{\mathrm{TM}}$ Potentiostat / Galvanostat / ZRA.

Electrochemical impedance spectroscopy. EIS measurements were done at $-1.0 \mathrm{~V}$ (vs SCE) after scale deposition process. The frequency range for EIS measurements was 0.1 to $1 \times 10^{4} \mathrm{~Hz}$ with applied potential signal amplitude of $10 \mathrm{mV}$. All the measurements were done at $40.0 \pm 0.1^{\circ} \mathrm{C}$ in solutions open to the atmosphere without stirring. To test the reliability and reproducibility of the measurements, triplicate experiments were performed in each case at the same conditions.

\section{Conclusions}

We report the synthesis of poly (5-nitro-orthanilic acid), a new type of polyaniline containing two types of functionalities by an aniline-initiated oxidative polymerization reaction. The nitro-orthanilic acid monomer itself did not polymerize under similar reaction conditions. The obtained polymer, as synthesized without further doping, was characterized with IR and UV spectroscopic techniques, elemental composition, cyclic voltammetry, viscosity, electrical conductivity, and dielectric measurements. SEM, TEM, TGA, DSC measurements were also investigated for additional analysis. Elemental analysis of carbon and nitrogen present is in good agreement with the given chemical formula of a modified polyaniline backbone. Analysis of sulfur contents resulted in an $\mathrm{S} / \mathrm{N}$ ratio $=0.66$ indicating a high content of substituted units in the resulted polymer backbone. The observed moderate reaction yield was expected because of the presence of electron-withdrawing groups which form a stable radical intermediate and the reaction occurs slowly due to electron density decreasing on the aniline' nitrogen atom. The presence of the hydrophilic $-\mathrm{SO}_{3} \mathrm{H}$ and a hydrophobic $-\mathrm{NO}_{2}$ groups on one aromatic ring gave the structure amphiphilicity or self-assembly nature and therefore the polymer morphology has a regular flower-leaf like microstructure as judged by SEM. The electronic spectra show absorption bands at $255 \mathrm{~nm}$, $380 \mathrm{~nm}$, and their bandgap energies were $4.86 \mathrm{eV}$ and $3.26 \mathrm{eV}$, respectively. Because of the random substitution of the monomers in such polymerization, substituents disrupt the conjugation length that results in a hypsochromic shift of $\pi-\pi^{*}$ and polaron- $\pi^{*}$ transitions. The voltammogram wave showed cathodic and anodic peaks corresponding to the quinoid and benzenoid structures, respectively, in the polymer main chain. Thermogravimetric measurements revealed high thermal stability up to $500^{\circ} \mathrm{C}$ and the degradation curves showed subsequent weight-losses within four steps in which the third(major peak) and fourth ones from $281^{\circ} \mathrm{C}-346^{\circ} \mathrm{C}$ and $345^{\circ} \mathrm{C}-466^{\circ} \mathrm{C}$, respectively, are likely due to decomposition and/or 
elimination processes of the side-chain substituents. The oxidative thermal decomposition of polymer backbones was suggested above $500^{\circ} \mathrm{C}$ for the polymeric remaining residues $(31 \%)$ as final weight loss. Differential thermogravimetric analysis unambiguously pointed out the glass temperature $\left(\mathrm{T}_{\mathrm{g}}\right)$ at $240^{\circ} \mathrm{C}$. The electrical conductivity decreases as the temperature increases at different applied frequencies. This behavior is indicative of semi-conducting nature in the extrinsic range which is characterized by high carriers and low mobility. The presence of such electron withdrawing residues causes a decrease of conductivity and increases the steepness of temperature dependence of conductivity. The dielectric measurements indicated that the permittivity, the measure of resistance, gradually decreased at the lower frequency range, up to $10 \mathrm{kHz}$, mainly due to the charge carriers' transport causing expected high conductivity. At a higher frequency range, up to $20 \mathrm{MHz}$, a slight effect was observed for frequency on decreasing the permittivity. Assessment of the copolymer as a new scale inhibitor of $\mathrm{CaSO}_{4}$, using the NACE test, indicated moderate $\mathrm{CaSO}_{4}$ inhibition efficiency, and this result is attributed to the change of polymer geometry via intramolecular $\mathrm{H}$-bonding interaction of the $-\mathrm{SO}_{3} \mathrm{H}$ group and the polymer chain in an aqueous medium. On the other hand, the copolymer exerted good $\mathrm{CaCO}_{3}$ inhibition with increasing inhibitor concentration despite the observed anomalous behavior. Thus, the above-mentioned features achieved by polymerization of (5-nitro-orthanilic acid) make the obtained polymer highly potential for application as a new multifunctional scaling inhibitor of $\mathrm{CaSO}_{4}$ and $\mathrm{CaCO}_{3}$ precipitation, the common problem in the industry. The noteworthy, derivatives-based monomer used in this work were actively used as sensing elements of optical sensors to determine sulfate in water and soil extracts.

\section{References}

1. Jamero, J., Zarrouk, S.J., Mroczek, E. Mineral scaling in two-phase geothermal pipelines: two case studies. Geothermics 72; 1; 10.1016/J.GEOTH ERMIC S.2017.10.015 (2018).

2. Kodel, K.A., Andrade, P.F., Valença, J.V.B., Souza, D.N. Study on the composition of mineral scales in oil wells. J. Pet. Sci. Eng. 81; 1; 10.1016/J.PETRO L.2011.12.007 (2012).

3. Dyer, S., Graham, G. The effect of temperature and pressure on oilfield scale formation. J. Pet. Sci. Eng. 35; 95; 10.1016/S0920 -4105(02)00217-6 (2002).

4. Amjad, Z., Landgraf, R.T., Penn, J.L. Calcium sulfate dihydrate (gypsum) scale inhibition by PAA, PAPEMP, and PAA/PAPEMP blend. Int. J. Corr Scale Inh.. 3; 35; 10.17675/2305-6894-2014-3-1-035-047 (2014).

5. a) Majeed, N. Polymeric materials for scale inhibition in cooling water systems. Tikritj. Eng. Sci. 18; 1; 10.25130/TJES.V.1812.111(2011). b) Popov, K. et al. new insight into the mechanism of the scale inhibition: DLS study of gypsum nucleation in presence of phosphonates using nanosilver dispersion as an internal light scattering intensity reference. Colloids Surf. A Physicochem. Eng. Asp. 560; 122; 10.1016/j.colsurfa.2018.10.015 (2019).

6. Yue, J., Gordon, G., Epstein AJ. Comparison of different synthetic routes for sulfonation of polyaniline. Polymer 33; 4410; 10.1016/0032-3861(92)90288-8 (1992).

7. Sarauli, D., Xu C., Dietzel, B., Schulz, B., Lisda, F. Differently substituted sulfonated polyanilines: The role of polymer compositions in electron transfer with pyrroloquinoline quinone-dependent glucose dehydrogenase. Acta Biomater.9; 8290; 10.1016/j.actbio.2013.06.008 (2013), and references cited therein. 
8. Ibrahim, K.A. Synthesis and characterization of polyaniline and poly(aniline-co-o-nitroaniline) Using vibrational spectroscopy. Arab J. Chem.10; S2668; 10.1016/j.arabjc.2013.10.010 (2017).

9. Shenglong, W., Fosong, W., Xiaohui, G. Polymerization of substituted aniline and characterization of the polymers obtained Synth. Met. 16; 99; 10.1016/0379-6779(86)90158-X (1986).

10. a) Rashid, M., Sabir, S. Oxidative copolymerization of aniline with $o$ - and $p$-nitroaniline by ammonium persulfate: kinetic and pathway. J. Dispers. Sci. Technol. 30; 297; 10.1080/01932690802540004 (2009). b) Waware, U.S.; Hamouda, A.M.S., Majumdar, D. Synthesis, characterization, and physicochemical studies of copolymers of aniline and 3-nitroaniline, Polym. Bull. 77; 4469 10.1007/s00289-019-02957-y (2020).

11. Ding, L., Li, Q., Zhou, D., Cui, H., Tang, R., Zhai, J. Copolymerization of aniline with m-nitroaniline and removal of $\mathrm{m}$-nitroaniline from $\mathrm{f}$ aqueous solutions using a polyaniline-modifed electrode: a comparative study. Electrochim Acta 77; 302; 10.1016/j.electacta.2012.06.012(2012).

12. Yu, M., Dedkov, N. V., Korsakova, Sychkova, V.A. New metallochromic indicator for barium: Determination of sulfate in water and soil extracts. J. Anal. Chem. 61 (12); 1154; 10.1134/S1061934806120057 (2006). b) Kuznetsov, V.V., Sheremet'ev, S. V. Sensing elements of optical sensors based on polystyrene with covalently immobilized reagents. J. Anal. Chem. 62 (3); 270; 10.1134/S1061934807030148 (2007).

13. a) Abd-El-Khalek, D. E., Hassan, H.H.A.M., Ramadan, S.R. Water-soluble sulfonated polyaniline as multifunctional scaling inhibitor for crystallization control in industrial applications. Chem. Eng. Res. Design 169; 135; 10.1016/j.cherd.2021.03.004 (2021). b) Zein El-Din, A.M., Hassan, H.H.A.M., Abou El-Kheir, M.M., Youssef, R.M.. Controlling soil surface crust formation using Nanosized sulfonated polyaniline. J. Soil Water Conserve. 1 (1), 001; (2016).

14. Chan, H. S. O.; Neuendorf, A. J.; Ng, S. C.; Wong, P. M. L.; Young, D. Synthesis of fully sulfonated polyaniline: a novel approach using oxidative polymerization under high pressure in the liquid phase. J. Chem. Comm. 1327; 10.1039/A802970I (1998).

15. Yue, J., Wang, Z. H., Cromack, K. R., Epstein, A. J., MacDiarmid, A. G. Effect of Sulfonic Acid Group on Polyaniline Backbone. J. Am. Chem. Soc. 113; 2665; 10.1021/ja00007a046 (1991).

16. Roy, B.C., Gupta, M.D., Ray, J.K. Studies on Conducting Polymers. 1. Aniline-Initiated Polymerization of Nitroanilines, Macromolecules. 28 (6); 1727; 10.1021/ma00110a001 (1995).

17. Stejskal J., Gilbert, R.G. (2002) Polyaniline. Preparation of a conducting polymer (IUPAC Technical Report). Pure Appl Chem 74; 857; 10.1351/pac200274050857 (2002).

18. Bilal, S., Gul, S., Holze, R., Anwar-ul-Haq, A.S. An impressive emulsion polymerization route for the synthesis of highly soluble and conducting polyaniline salts. Synth. Met. 206; 131; 10.1016/j.synthmet.2015.05.015 (2015).

19. a) Kazuo, A. Advances in Liquid Crystalline Conjugated Polymers. J. Polym. Sci. A Polym. Chem. 47; 2463; 10.1002/pola.23277(2009). b) A. Kazuo. Synthesis and Properties of Liquid-Crystalline-Conjugated Polymers. Bull. Chem. Soc. Japan. 8; 649; 10.1246/bcsj.80.649 (2007).

20. Isakova, A.A. et al. The Synthesis of Polyaniline in Polyethylene Films with Grafted Sulfonated Polystyrene and Properties of These Films. Prot. Met. Phys. Chem. Surf. 56; 725; 10.1134/S2070205120040127 (2020).

21. Gizdavic-Nikolaidis, M.R., Bennett, J.R., Swift, S., Easteal, A.J., Ambrose, M. Broad spectrum antimicrobial activity of functionalized polyanilines. Acta Biomater. 7; 4204; 10.1016/j.actbio.2011.07.018 (2011). 
22. Thiemann, C., Brett, C.M.A. Electropolymerisation and properties of conducting polymers derived from aminobenzenesulphonic acids and from mixtures with aniline. Synth. Met.125; 445; 10.1016/S03796779(01)00502-1 (2001).

23. Zhang, Y., Kim, J.J., Chen, D., Tuller, H.L., Rutledge, G.C. Electrospun Polyaniline Fibers as Highly Sensitive Room Temperature Chemiresistive Sensors for Ammonia and Nitrogen Dioxide Gases. Adv. Funct. Mater. 24; 4005; 10.1002/adfm.201400185 (2014).

24. Scotto, J., Florit, M., Posadas, D. About the species formed during the electrochemical half oxidation of polyaniline: Polaron-bipolaron equilibrium Electrochim. Acta. 268; 187; 10.1016/j.electacta.2018.02.066 (2018).

25. Bacon, J., Adams, R. N. Anodic oxidations of aromatic amines. III. Substituted anilines in aqueous media. J. Am. Chem. Soc. 90 (24); 6596; 10.1021/ja01026a005 (1968).

26. Xu, Y., Dai, L., Chen, J., Gal, J.Y., Wu, H. Synthesis and characterization of aniline and aniline- $o$-sulfonic acid copolymers. Eur. Polym. J. 43; 2072; 10.1016/j.eurpolymj.2006.09.017 (2007).

27. Andriianova,A., Biglova, Yu., Mustafin, A. Effect of structural factors on the physicochemical properties of functionalized polyanilines. $R S C A d v .10 ; 7468 ; 10.1039 /$ C9RA08644G (2020).

28. Wang, S., Wang, F., Ge, X. Polymerization of substituted aniline and characterization of the polymers obtained. Synth. Met. 16; 99; 10.1016/0379-6779(86)90158-X (1986).

29. Gorshkov, N.V. et al. Dielectric properties of the polymer-matrix composites based on the system of Co-modified potassium titanate-poly tetrafluoroethylene, J. Compos. Mater. 52 (1); 135; 10.1177/0021998317703692 (2018).

30. Moussa, M.A., Abdel Rehim, M.H., Turky, G.M. Anomalous activation behavior of the conductivity mechanisms in polyaniline-doped graphitic carbon nitride. J. Phys. Chem. Solids. 158; 110243; 10.1016/j.jpcs.2021.110243 (2021).

31. Scott, A.H., Curtis, D.L., Auritzenandj, A.L.L., Res, D.J. Dielectric Properties of Semicrystalline Poly chlorotrifluoroethylene. Nalt. Bur. Stand, Soc A. 66; 269; 10.6028/jres.066A.028 (1962)

32. Islam, N., Gafur, M.A., Khan, A. H. Conduction Mechanism and Conductivity Behavior of Pure Polypropylene (PP) and Polypropylene-Banana Fiber (PP-B) Composites. J. Build. Mat. Sci., 02;16;10.30564/jbms.v2i2.2870 (2020).

33. Adrien, P., Coté, A.P., Shimizu, G.K.H. The supramolecular chemistry of the sulfonate group in extended solids. Coord. Chem. Rev. 245; 49; 10.1016/S0010-8545(03)00033-X (2003).

34. a) Abd El-Aziz, M. E., Youssef, A.M., Abd El-Sayed, E.S., Moussa, M.A., Turky, Kamel, G.S. Rational design and Electrical study of hydrogel based on Polyacrylic Acid/Polypyrrol/Silver Nanoparticles @ Chitosan. Int. J. Bio. Macromol. 140; 886; 10.1016/j.ijbiomac.2019.08.199 (2019). b) Kremer, F. Dielectric spectroscopy-yesterday today and tomorrow, J. Non-Cryst. Solids 305; 1; 10.1016/S0022-3093(02)01083-9 (2002). c) Turky, G.M., ElAdly, R.A. Study of phase separation and anomalous molecular behavior of Jojoba oil using dielectric spectroscopy. J. Mol. Liq. 242; 1; (2017).

35. a) NACE Standard. Laboratory Screening Tests to Determine the Ability of scale Inhibitors to Prevent the Precipitation of Calcium Sulfate. T.M.0374-2001; Item 21208 (2001). b) Boris, A.M., Alla, Y. F., Margarita, A.K.. NACE Corros., 07064 (2007). 


\section{Author contributions}

H.H.: Developed and supervised the research point, performed the experimental preparation, analyzed all characterization data, and put all data into writing in the final form. D.A.: Performed the experimental part of precipitation inhibition, analyzed the data, and write the draft of the discussion of this section. M.A.: Performed the electrical conductivity measurements, analyzed the data, and write the draft of discussion of this section. All authors discussed the results and contributed to the final manuscript.

\section{Competing interests}

The authors declare no competing interests.

\section{Data availability}

All data generated or analyzed during this study are included in this published article. 